\title{
The social and vocational outcome of spinal cord injury patients
}

\author{
M Taricco MD,${ }^{1} \mathrm{C}$ Colombo MD ${ }^{1} \mathrm{R}$ Adone MD,${ }^{1} \mathrm{G}$ Chiesa MD,${ }^{1} \mathrm{~S}$ Di Carlo MD ${ }^{1}$ \\ M Borsani Pt, ${ }^{1}$ E Castelnuovo Pt, ${ }^{1} \mathrm{G}$ Ghirardi Pt, ${ }^{1} \mathrm{R}$ Lascioli $\mathrm{Pt}^{1}$ and A Liberati $\mathrm{MD}^{2}$ \\ ${ }^{1}$ Unità Spinale Integrata SRRF, Ospedale Casati, Passirana di RHO (MI), Italy; \\ ${ }^{2}$ Laboratorio di Epidemiologia Clinica, Istituto Mario Negri, Milano, Italy.
}

\begin{abstract}
Functional status, perception of adjustment, occupational outcome and social functioning were investigated in a group of spinal cord injury (SCI) patients (mean age 34, range 10-74 years) seen at a specialised spinal unit over the period January 1984-December 1988. Functional status was assessed using a standardised scale measuring patients' performance of specific tasks, and other measures of outcome were investigated by a structured interview. Almost two thirds $(68 \%)$ of the patients were independent according to the standardised scale (33\% quadriplegic and $84 \%$ paraplegic). Patients' autonomy appeared to be threatened by architectural barriers in and about the house: approximately one third (34\%) of those classified as 'independent' on the standardised rehabilitation scale used needed some help in their everyday life. A negative occupational outcome emerged: compared to the pre-morbid situation, 43 patients $(44 \%)$ were worse off; $48(49 \%)$ did not experience substantial changes-though it must be noted that $68 \%$ of these $(33 / 48)$ were virtually unemployed (ie student, home maker, retired, unemployed) before the injury; and for $6(7 \%)$ some improvement took place. With a multivariate analysis age was the only statistically significant predictor of poor occupational outcome, with older patients being worse off irrespective of the extent of disease and functional autonomy. The paper discusses these results and stresses the need for integrating results based on the use of standardised rehabilitation scales with the analysis of potential barriers influencing a patient's ability to exploit his/her autonomy.
\end{abstract}

Key words: spinal cord injury; outcome; employment; rehabilitation; follow up studies.

\section{Introduction}

Over the last few years increasing attention has been paid to the quality of life of patients with chronic conditions. ${ }^{1}$ Rehabilitation of patients with spinal cord injuries (SCI) was until recently focused essentially on relieving the clinical consequences of their impairment (survival, complications, etc). However, medical management of SCI patients has now shifted from an emphasis on physical measures of outcome to an attempt to better understand factors that affect their quality of life. Treatment and management have in fact advanced to the point that these patients' life expectancy is beginning to approach that of the general population.

Although the quality of life of patients with SCI is obviously multidimensional, it can clearly be seriously affected by the environment ${ }^{2}$ in addition to personal and disease related factors. Most of the existing literature has focused on the latter, particularly on factors specific to the individual-ie medical complications, independence in daily living, psychological adjustment to injury, motivation and willingness to cooperate with rehabilitation staff ${ }^{2-4}$ or employment status. ${ }^{5}$

The present study was planned with the following aims: (1) to describe the occupational and social outcomes of SCI patients; (2) to compare their own assessment of independence in activities of daily living against an 'objective' (external) measure of it; and (3) to explore the associations 
between functional status, sociodemographic characteristics and type of injury.

Our findings are consistent with those in the published literature, but they are worth interpreting specifically within the context of the Italian health care system where the rights of disabled patients are still largely neglected and where compliance to laws on architectural barriers and re-employment are seldom enforced.

\section{Patients and methods}

Source population and coverage of the study

All consecutive patients seen at the Unità Spinale Integrata of Passirana Hospital between January 1984 and December 1988 $(n=122)$ were eligible for the study. According to the study protocol, they were all invited by telephone to attend as outpatients to be assessed as to their functional status and interviewed using a standardised questionnaire (see below). Sociodemographic information was taken (age, sex, education, living arrangements) and each patient was classified according to: (1) the level of his/her spinal lesion (defined as the lowest normally functioning spinal segment); (2) the extent of the disease (complete or incomplete); and (3) its aetiology (traumatic or other). Seventy-four (61\%) patients attended the outpatient visit, 23 (19\%) refused but agreed to answer a telephone interview, $8(6 \%)$ were dead at the time of the follow-up visit; the remaining 17 (14\%) could not be traced as they had moved or were being cared for in institutions outside the geograhic area covered by the project.

\section{The questionnaire and follow up visit}

The personal and occupational situation was investigated by an interview (average time 20 minutes) carried out by 4 of the physicians in charge of the study using a fixed-format standardised questionnaire divided into 4 sections: (1) occupational status (with reference to the time of disease occurrence and that of the index interview), satisfaction with it and with current income; (2) living arrangements in terms of adequacy of present housing and of architectural barriers; (3) leisure activities in terms of time spent with friends, practising sports, attending social activities and hobbies; (4) health status in terms of SCI related complications, hospital admissions and self rating of overall health.

Functional status was 'objectively' assessed during the outpatient follow up visit by one of the 4 physiotherapists in the study, using a standardised scale developed by 2 of the authors (MT/CC). The scale maps 8 different areas, each including a variable number of tasks ranging from 6 (for feeding) to 14 (for use of wheelchair). The scale specifically explores the following areas: (1) ability to change position (from supine to prone, etc); (2) drinking and feeding (ie use of fork, knife, glass, etc); (3) ability to transfer (ie from bed to chair, from bed to wheelchair, etc); (4) ability to move the wheelchair; (5) toilet (ie washing and bathing); (6) dressing; (7) ability to use household facilities (ie elevator, TV, etc); (8) walking. Depending on the performance for each task, a score from 0 to 4 is assigned based on the following criteria: $4=$ when the patient is able to carry out the task and does not require any assistance; $3=$ as above, but needing a device to help in the execution of the task; $2=$ when the patient requires help by the examiner in the execution of the task; $1=$ when the patient needs major assistance; $0=$ when the patient is unable to carry out the task. Though the maximum achievable score in the whole test is 268, operationally only area-specific scores are considered and final judgment is based on their separated consideration.

Inter-rater reliability of the scale has already been measured ${ }^{6}$ it was good in at least 5 out of 7 areas $(K=0.70)$ and acceptable in the remaining two $(\mathrm{K}=$ $0.40)^{7}$

Information obtained from the patients' own reporting and from the objective assessment of functional status made it possible to compare subjective and objective assessments of adjustment; this is reported as the amount of help that both dependent and independent patients reported they needed.

\section{Data analysis}

The measure of functional status was calculated as follows. Scores for each area of 
activity were first computed as the ratio of the sum of scores obtained in each component area (numerator) to the sum of highest achievable score (denominator), and the results were expressed in percentages. In each area of activity the cut-off value to separate good and bad scores was $75 \%$. An overall summary score was then computed using the same cut-off point for the composite score: only those patients with a score $\geqslant 75 \%$ in all seven areas of activity were classified 'independent'. Those with a performance score $<75 \%$ in at least area were classified as 'dependent'.

Except for functional status (assessed only among the 74 patients attending the follow up visit) results are presented for the whole group of 97 patients in aggregate, because no statistically significant difference in any sociodemographic variable emerged between those with personal or phone interview.

Differences between means and proportions were analysed using the unpaired tand the chi-square test for heterogeneity, respectively. The reciprocal confounding effects of factors associated with functional status (automony) and occupational outcome were assessed by multivariate analysis using the logistic regression method. ${ }^{8}$ In the equation exploring predictors of functional status (dependent variable) the following were included: age and education (continuous variables), sex, diagnosis (paraplegia or quadriplegia) and presence of coexistent disease(s) (yes/no). In the equation exploring predictors of occupational outcome another variable was added: presence/absence of architectural barriers. Coefficients obtained from the logistic regression equations were transformed into their corre- sponding 'odds ratios' - together with their $95 \%$ confidence intervals $(95 \% \mathrm{CI})-$ indicating the probability of being independent or having a better occupational outcome at the time of the follow up visit.

\section{Results}

General characteristics of the sample

The sociodemographic characteristics of the 97 patients enrolled in the study are shown in Table I: $74 \%$ patients were males and about half were older than 35 ; one third had 9 or more years of education. Thirty-one $(32 \%)$ patients were quadriplegic, $41(42 \%)$ paraplegic with a thoracic lesion, and 25 $(26 \%)$ paraplegic with a lumbar lesion; 47 (48\%) patients had a complete lesion and 50 $(52 \%)$ incomplete. In $79 \%$ of patients the disease was of traumatic origin. The mean follow up time from the event was 3.7 years (range 1.0-6.1) with $46 \%$ patients suffering an impairment lasting 1-3 years and the remaining $54 \% 4-6$ years.

\section{Functional status and perception of adjustment}

The functional status could only be assessed for the 74 patients willing to attend the follow up visit. Table II shows their classification according to the different areas explored by the standardised scale. No association emerged between functional status and sociodemographic variables.

The scale was highly discriminant between quadriplegic and paraplegic patients: $33 \%$ and $84 \%$, respectively, were classified as independent $(\chi 2=19.1 p<0.001)$. This corresponded to a $92 \%$ lower probability $(\mathrm{OR}=0.08 ; \quad 95 \% \quad \mathrm{CI}=0.02-0.39) \quad$ of $\mathrm{a}$

Table I Sociodemographic characteristics of the 97 patients enrolled into the study

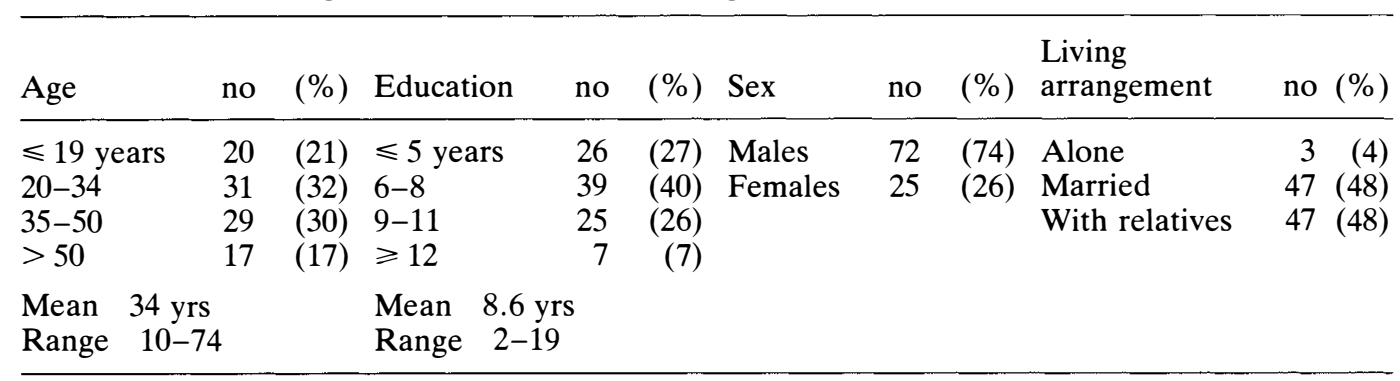


quadriplegic patient being classified as independent by the scale.

Comparison between objective and subjective assessments of adjustment (see methods) indicated that, as expected, dependent patients needed assistance more than independent ones (Table III) $(87 \%$ vs $34 \%$ ). Among these latter, most said they needed assistance for only a few hours per day, and the remaining 7 for half a day or less (Table III). In this latter group almost all patients $(15 / 17)$ reported the presence of some form of architectural barriers in and about the home. This was confirmed by the other answers to the questionnaire (data not shown) where these patients reported the need for some help for very short periods, mostly because of architectural barriers.

\section{Occupational outcome and social functioning}

The distribution of the patient's occupational status before the disease and at the

Table II Performance of the 74 patients* seen at follow-up visits

\begin{tabular}{lcrrr}
\hline Area of activity & \multicolumn{3}{c}{ Independent } & \multicolumn{2}{c}{ Dependent } \\
\hline & no & $(\%)$ & no & $(\%)$ \\
Postural changes & 63 & $(85)$ & 11 & $(15)$ \\
Feeding & 68 & $(91)$ & 6 & $(9)$ \\
Transfer abilities & 53 & $(72)$ & 21 & $(28)$ \\
Use of wheelchair & 56 & $(76)$ & 18 & $(24)$ \\
Personal care & 69 & $(93)$ & 5 & $(7)$ \\
Dressing & 59 & $(80)$ & 15 & $(20)$ \\
Social activities & 68 & $(91)$ & 6 & $(9)$ \\
\hline
\end{tabular}

*Fifty $(68 \%)$ of these patients were independent and $24(32 \%)$ were dependent. time of the interview is shown in Table IV, based on the answers of those seen at the follow up visit and non attenders interviewed by telephone. Compared to the pre-morbid situation, 43 patients were worse off, 48 had not experienced substantial changes - though it must be noted that two thirds of these were virtually unemployed before the injury (ie student, homemaker, retired, unemployed)-and 6 reported some improvement.

As expected, patients with a worse occupational outcome more often found their income reduced $(76 \%$ vs $22 \%$ of those with stable situation, $\chi 2=29.2, p>0.001)$, particularly if they were older $(59 \%$ vs $31 \%$ among younger, $\chi 2=7.3 p>0.01)$, and less educated $(51 \%$ vs $31 \%$ among those with 8 or more years of education, $\chi 2=3.5$, $p=0.06)$. All these associations held true even after controlling for imbalances in the mix of types of lesion within groups. Age, in particular, remained a significant predictor of occupational outcome in multivariate analysis. The probability of a better outcome was almost $50 \%$ (OR $=1.43 ; 95 \%$ $\mathrm{CI}=1.02-1.99)$ higher for every 10 years of younger age.

Contrary to expectations, occupational outcome was not necessarily associated with functional status even though dependent subjects were slightly over represented among those unable to keep their own job.

Forty-five $(50 \%)$ subjects said they were able to live alone and $52(54 \%)$ reported some need for assistance during the day. Only $20(21 \%)$ of them, however, had spent at least 3 days by themselves since their impairment began, when the question was posed directly.

Table III Perceived need of help of subjects with various degree of functional autonomy

\begin{tabular}{ccccccccc}
\hline & \multicolumn{3}{c}{ Perceived need of help } & \multicolumn{3}{c}{ Amount of help required } \\
& $\begin{array}{c}\text { None } \\
\text { no } \\
(\%)\end{array}$ & $\begin{array}{c}1 \text { person } \\
\text { no } \\
(\%)\end{array}$ & $\begin{array}{c}2 \text { people } \\
\text { no } \\
(\%)\end{array}$ & $\begin{array}{c}<1 / 2 \\
\text { hour } \\
\text { no } \\
(\%)\end{array}$ & $\begin{array}{c}<\text { Half } \\
\text { day } \\
\text { no } \\
(\%)\end{array}$ & $\begin{array}{c}\text { Half a } \\
\text { day } \\
\text { no } \\
(\%)\end{array}$ & $\begin{array}{c}\text { Whole } \\
\text { day } \\
\text { no } \\
(\%)\end{array}$ & $\begin{array}{c}\text { Day and } \\
\text { night } \\
\text { no } \\
(\%)\end{array}$ \\
\hline $\begin{array}{c}\text { Dependent } \\
\text { patients }\end{array}$ & 3 & 19 & 2 & 2 & 12 & 3 & 1 & 3 \\
$\begin{array}{c}\text { Independent } \\
\text { patients }\end{array}$ & $(13)$ & $(79)$ & $(8)$ & $(10)$ & $(57)$ & $(14)$ & $(5)$ & $(14)$ \\
\hline
\end{tabular}


Table IV Occupational status before the injury and at follow-up visit

\begin{tabular}{lrrrr}
\hline & $\begin{array}{c}\text { Occupational } \\
\text { status before } \\
\text { the injury }\end{array}$ & \multicolumn{2}{c}{$\begin{array}{c}\text { Occupational } \\
\text { status at } \\
\text { follow up }\end{array}$} \\
\hline & no & $(\%)$ & no & $(\%)$ \\
Unemployed & 7 & $(7)$ & 25 & $(26)$ \\
Occupied & 64 & $(66)$ & 31 & $(32)$ \\
Student & 14 & $(15)$ & 15 & $(16)$ \\
Home maker & 8 & $(8)$ & 13 & $(13)$ \\
Retired & 4 & $(4)$ & 13 & $(13)$ \\
\hline
\end{tabular}

Change in status

\begin{tabular}{lrr}
\hline Worse & 43 & $(44)$ \\
Unchanged & 48 & $(49)$ \\
Better & 6 & $(7)$ \\
\hline
\end{tabular}

Approximately half the patients reported a decrease in at least one of the 3 indicators of social functioning (interactions with friends, attendance at cultural and social events), but this impairment affected all 3 areas investigated in only 13 subjects. Such impairment was mostly (83 to 87 ) consequent to the disease and only a tiny minority of subjects $(9 \%)$ reported more frequent interactions with friends and attendance at social events.

Overall, occupational outcome was not associated with any of these indicators of social functioning.

\section{Discussion}

Only a few studies have looked at the occupational and social outcome of SCI patients in Italy and elsewhere. ${ }^{2,3,5,9}$ In the present survey the good participation of patients and the relatively long observation period (mean 3.17 years since disease inception) are 2 aspects to be kept in mind when critically assessing our findings.

Our study confirmed that SCI had a substantial negative impact in terms of occupational status and consequently also on income for many patients. Older age appeared to be the most important predictor of negative occupational outcome, independent of other factors commonly taken as equally, if not even more, important such as the type of lesion and duration of disease.

Quite unexpected was the lack of association between functional status and occupational outcome. If true, this might suggest that factors (ie social or economic) other than functional status and independence per se affect the likelihood of keeping the pre-disease occupation.

Moreover, as many patients in wheelchairs were 'independent' by our scale, the ability to walk may be a major factor in occupational outcome, at least for specific jobs.

There was good agreement between subjective assessment of independence and the standardised scale results. The scale appeared to discriminate well between the types of impairment typical of major (quadriplegic vs paraplegic) and-within the latter group-minor categories of patients (thoracic vs lumbar paraplegic).

Comparison of objective and subjective perception of adjustment suggests that although independence is not fully accounted for by functional status (see the findings on perceived need for assistance by dependent and independent subjects), the burden caused by SCI is indeed different depending upon the degree of autonomy (Table III).

Finally our study confirmed the importance of the assessment of architectural barriers - and their bearing on daily living activities - in correctly interpreting the predictive value of standardised evaluation of functional status and independence. We obviously cannot rule out that a lack of sensitivity of our scale may have been responsible for our finding that a few independent patients still reported the need for some help at home. However, this inconsistency could in fact be only apparent: standardised examination is carried out in hospital, whereas architectural barriers can act against patients' independence any time during their home life. If this is true, then any standardised examination of independence should incorporate a careful assessment of the barriers influencing patients' ability to exploit their autonomy. 


\section{References}

1 Katz S, Branch LG, Branson MH, Parsidero JA, Beck JC, Greer DS (1983) Active life expectancy. N Engl J Med 309: 1218-1224.

2 DeJong G, Branch LG, Corcoran PJ (1984) Independent living outcomes in spinal cord injury: multivariate analyses. Arch Phys Med Rehabil 65: 66-73.

3 Yarkony GM (1988) Functional skill after spinal cord injury rehabilitation: three-year longitudinal follow-up. Arch Phys Med Rehabil 69: 111-114.

4 Zola IK (1982) Social and cultural disincentives to independent living. Arch Phys Med Rehabil 63: 394-397.

5 De Vivo MJ, Rutt RD, Stover SL, Fine PR (1987) Employment after spinal cord injury. Arch Phys Med Rehabil 68: 494-498.

6 Taricco M, Grandi A, Colombo C, Liberati A (1991) La valutazione della autonomia funzionale nel paziente medulloleso: studio sulla riproducibilità di un nuovo test. Europa Med Phys 27: 85-90.

7 Fleiss JL (1981) Statistical methods for rates and proportions. John Wiley \& Sons, New York.

8 Schlesselman JJ (1982) Case Control Studies: Design, Conduct and Analysis. Oxford University Press, Oxford.

9 De Vivo MJ, Fine PR (1982) Employment status of spinal cord injured patients 3 years after injury. Arch Phys Med Rehabil 63: 200-203. 